\title{
Associations between the intake of caffeinated and decaffeinated coffee and measures of insulin sensitivity and beta cell function
}

\author{
R. C. Loopstra-Masters - A. D. Liese • S. M. Haffner • \\ L. E. Wagenknecht • A. J. Hanley
}

Received: 30 April 2010 /Accepted: 8 October 2010 /Published online: 3 November 2010

(C) Springer-Verlag 2010

\begin{abstract}
Aims/hypothesis Although protective relationships between coffee consumption and type 2 diabetes mellitus have consistently been observed, few studies have examined the relationships between coffee consumption and underlying pathophysiological defects that characterise diabetes aetiology. The aim of this study was to explore the associations between caffeinated and decaffeinated coffee consumption and measures of insulin sensitivity and secretion.

Methods The study population included 954 multi-ethnic non-diabetic adults from the Insulin Resistance Atherosclerosis Study (IRAS). Multiple regression analyses were performed to examine the cross-sectional relationships between caffeinated and decaffeinated coffee intake and insulin sensitivity and acute insulin response, measured by
\end{abstract}

R. C. Loopstra-Masters · A. J. Hanley ( $\square)$

Department of Nutritional Sciences, Faculty of Medicine,

University of Toronto,

FitzGerald Building, 150 College St,

Toronto, ON, Canada M5S 3E2

e-mail: anthony.hanley@utoronto.ca

A. D. Liese

Department of Epidemiology and Biostatistics,

University of South Carolina,

Columbia, SC, USA

S. M. Haffner

Division of Cardiology, Department of Medicine,

Baylor College of Medicine,

Houston, TX, USA

L. E. Wagenknecht

Division of Public Health Sciences, School of Medicine,

Wake Forest University,

Winston-Salem, NC, USA a frequently sampled intravenous glucose tolerance test, $2 \mathrm{~h}$ postload glucose measured by OGTT, fasting insulin, and proinsulin to C-peptide ratios.

Results Caffeinated coffee intake was positively associated with insulin sensitivity $(\beta=0.054 ; \mathrm{SE}=0.026 ; p=0.04)$ and inversely related to $2 \mathrm{~h}$ postload glucose $(\beta=-0.37$; $\mathrm{SE}=$ $0.10 ; p=0.0003$ ) in fully adjusted models. Caffeinated coffee intake was not associated with acute insulin response or proinsulin ratios. Decaffeinated coffee intake was inversely related to $2 \mathrm{~h}$ postload glucose $(\beta=-0.47 ; \mathrm{SE}=0.18 ; p=$ $0.0096)$ and positively related to acute insulin response $(\beta=$ 0.191; $\mathrm{SE}=0.077 ; p=0.0132$ ). Decaffeinated coffee intake was inversely related to the ratios of both intact and split proinsulin to $\mathrm{C}$-peptide $(\beta=-0.150 ; \mathrm{SE}=0.061 ; p=0.0148$; $\beta=-0.254 ; \mathrm{SE}=0.068 ; p=0.0002$, respectively).

Conclusions/interpretation In this cross-sectional study, caffeinated coffee was positively related to insulin sensitivity and decaffeinated coffee was favourably related to measures of beta cell function. These results provide pathophysiological insight as to how coffee could impact the risk of type 2 diabetes mellitus.

Keywords Beta cell function · Coffee - Insulin sensitivity · Type 2 diabetes mellitus

$\begin{array}{ll}\text { Abbreviations } \\ \text { AIR } & \text { Acute insulin response } \\ \text { FFQ } & \text { Food frequency questionnaire } \\ \text { FSIGT } & \begin{array}{l}\text { Frequently sampled intravenous glucose tolerance } \\ \text { test }\end{array} \\ \text { IGT } & \text { Impaired glucose tolerance } \\ \text { IQR } & \text { Interquartile range } \\ \text { IRAS } & \text { Insulin Resistance Atherosclerosis Study } \\ \text { NGT } & \text { Normal glucose tolerance } \\ \mathrm{S}_{\mathrm{I}} & \text { Insulin sensitivity }\end{array}$




\section{Introduction}

In the past decade, there has been accumulating evidence that both caffeinated and decaffeinated coffee consumption are associated with a lower risk of type 2 diabetes mellitus, as affirmed recently in a meta-analysis [1]. Although the data suggest a protective effect of coffee consumption on type 2 diabetes mellitus risk, there remain some questions regarding underlying mechanisms. Specifically, there have been very few studies that have examined the relationship between coffee intake and insulin resistance and beta cell function [2-4], the two critical underlying traits of diabetes pathogenesis. Exploring these relationships is essential to gaining a pathophysiological understanding of the protective relationship that has been observed between coffee consumption and diabetes.

Therefore, the objective of this study was to examine the cross-sectional relationships between caffeinated and decaffeinated coffee consumption and fasting insulin, insulin sensitivity $\left(\mathrm{S}_{\mathrm{I}}\right)$ and acute insulin response (AIR) measured by a frequently sampled intravenous glucose tolerance test (FSIGT), $2 \mathrm{~h}$ postload glucose, and proinsulin to C-peptide ratios, in a multi-ethnic study population from the USA.

\section{Methods}

Study population and design The Insulin Resistance Atherosclerosis Study (IRAS) is a multi-centre prospective cohort study that was initiated in 1992 to study the relationships among insulin resistance, cardiovascular disease and related risk factors. A detailed description of the recruitment methods and study design has been published previously [5]. Briefly, the study was based at four study centres located in San Antonio (TX, USA), San Luis Valley (CO, USA), Oakland (CA, USA) and Los Angeles (CA, USA). The recruitment strategy aimed to include equal numbers of adults in the age ranges of 40-49, 50-59, and 60-69 years, who were non-Hispanic white, Hispanic and African-American, with normal glucose tolerance (NGT), impaired glucose tolerance (IGT), and non-insulin treated type 2 diabetes mellitus. A total of 1,625 participants was included in the baseline IRAS population. All study participants gave written informed consent and research ethics approval was obtained from the institutional review boards at each study centre [5].

For the current study, the population was restricted to individuals without type 2 diabetes mellitus at baseline, classified by the 1999 WHO guidelines or by documented use of oral hypoglycaemic medication $(n=1,066)$. Participants were also excluded if their energy intake was beyond the sex-specific 1st and 99th percentiles of 2,722 and $20,932 \mathrm{~kJ} /$ day for men, and 2,222 and $15,468 \mathrm{~kJ} /$ day for women, resulting in a study population of 1,030 . As a result of missing $\mathrm{S}_{\mathrm{I}}$ and AIR data, the population was further reduced from 1,030 to 954 .

Data collection The IRAS study protocol included two study visits approximately 1 week apart to allow for both an OGTT and FSIGT to be conducted. Participants were instructed to come fasted for $12 \mathrm{~h}$ prior to each study visit, to abstain from alcohol and exercise in the $24 \mathrm{~h}$ before each study visit, and to abstain from smoking the morning of the study visit [5].

Anthropometric measures included height and weight measured to the nearest $0.5 \mathrm{~cm}$ and $0.1 \mathrm{~kg}$, respectively [5]. Information on ethnicity, age and highest level of education attained were obtained by self-report. A family history of diabetes was considered to be the presence of diabetes in a parent or sibling. A validated physical activity questionnaire that requested information on physical activity in home, workplace and leisure environments was used to estimate energy expenditure over the past year [6]. Information on alcohol consumption and smoking habits was collected by questionnaire to assess present and past habits.

Data on food and beverage consumption, including coffee consumption, were collected through the use of a 114-item food frequency questionnaire (FFQ) that was a modified version of the National Cancer Institute Health Habits and History Questionnaire. It was expanded to include food items appropriate for the diverse IRAS study population and was validated in a sub-sample [7]. The FFQ included nine frequency options for each food item or group of related items, ranging from 'never or less than once a month' to 'six or more times per day'. Participants provided information on their regular portion size for each item by indicating whether their portions were 'small, medium or large compared with other men or women about your age'. To calculate intakes of items, the intake frequency was weighted by the portion size response, specifically a factor of $0.5,1$ and 1.5 , for small, medium and large, respectively. Therefore, one serving of any item in the beverage or food groupings corresponds to a participant-identified medium sized serving. Data on coffee intake came from two questions of the FFQ which specifically addressed intake of caffeinated coffee and decaffeinated coffee. Intakes of these two items were added together to give a measure of total coffee intake. In addition, the FFQ included three questions that addressed intake of additives to hot beverages, specifically, 'milk added to coffee or tea', 'cream added to coffee or tea', and 'sugar or honey added to coffee or tea'.

Wholegrain intake, vegetable intake and fruit intake were calculated to be consistent with previous food grouping work in the IRAS population [8]. Energy intake and per cent energy intake from saturated fat came from the 
nutrient analysis of the FFQ data through the use of the HHHQ-DIETSYS analysis software (version 3.0, 1993; National Cancer Institute, Bethesda, MD, USA).

Glucose tolerance and 2-h postload glucose An OGTT was performed on the first of the 2 days of study visits. A fasting blood sample was taken and followed by the administration of a $75 \mathrm{~g}$ glucose load (Orange-dex; Custom Laboratories, Baltimore, MD, USA), which was consumed by study participants within $10 \mathrm{~min}$. A second blood sample was taken after $2 \mathrm{~h}$. Participants were classified as diabetic if their fasting plasma glucose was $\geq 7.0 \mathrm{mmol} / 1$ or their $2 \mathrm{~h}$ plasma glucose was $\geq 11.1 \mathrm{mmol} / 1$ (these individuals were excluded from the present analysis). Participants were classified as having IGT if their fasting plasma glucose was $<7.0 \mathrm{mmol} / \mathrm{l}$ and their $2 \mathrm{~h}$ plasma glucose sample was $\geq 7.8$ and $<11.1 \mathrm{mmol} / 1$. Plasma glucose measurements were obtained by glucose oxidase technique on an automated autoanalyser (Yellow Springs Equipment, Yellow Springs, Ohio, USA).

Insulin sensitivity and secretion measures An FSIGT was used to obtain measures of insulin resistance and insulin secretion. A modified protocol was adopted so that the FSIGT was appropriate for use in those with diabetes and to accommodate the large number of study participants. These modifications included the use of an injection of insulin rather than tolbutamide, and the use of a reduced-sampling protocol that utilised 12 plasma samples rather than 30 [5].

$\mathrm{S}_{\mathrm{I}}$ was calculated by the use of mathematical modelling methods (MINMOD version 3.0, 1994, Los Angeles, CA). The mean insulin concentration at time-points 2 and 4 min following the initial injection of glucose was used as the AIR value.

Serum insulin was measured by the dextran-charcoal RIA, which displays a high-degree of cross-reactivity with proinsulin. The CV was $19 \%$ ( $n=163$ split-pairs). Highlyspecific two-site monoclonal antibody-based immunoradiometric assays were used to separately measure serum intact proinsulin and split proinsulin, with split pair CVs of $14 \%$ $(n=98)$ and $18 \%(n=98)$, respectively. Insulin did not significantly cross-react in either assay. The intact proinsulin assay did not significantly cross-react with split proinsulin. The split proinsulin assay was equally crossreactive with 32-33, des-32, and des-31-32 split proinsulins, so the term 'split proinsulin' is used in the present paper to refer to the grouping of all three molecules. In addition, the split proinsulin assay had $84 \%$ cross-reactivity with intact proinsulin [9]. To correct for this cross-reactivity, the corresponding intact proinsulin cross-reactivity was subtracted from the assay values of split proinsulin. For all analyses, proinsulin values were divided by fasting Cpeptide concentration, designated 'proinsulin to C-peptide ratio', to assess disproportionate hyperproinsulinaemia.
Statistical analysis All statistical analyses were conducted with SAS version 9.1 (SAS Institute, Cary, NC). Participant characteristics were tested for differences across coffee intake categories. Differences in frequencies were tested by $\chi^{2}$ tests for categorical variables. Differences in means were tested by ANOVA for continuous variables, except in the case of dietary variables which were tested by ANCOVA (analysis of covariance), adjusted for energy intake, and for continuous variables that were highly skewed. The latter included all $\mathrm{S}_{\mathrm{I}}$ and beta cell function measures and estimated energy expenditure. These variables were tested for differences across coffee intake categories by the nonparametric Kruskal-Wallis test.

Linear regression analyses were used to examine the relationships between coffee intakes modelled as continuous variables and $2 \mathrm{~h}$ postload glucose, fasting insulin, $\mathrm{S}_{\mathrm{I}}$, AIR (adjusted for $\mathrm{S}_{\mathrm{I}}$ ), and intact and split proinsulin to $\mathrm{C}$ peptide ratios. For these analyses, $\log _{\mathrm{e}}$ transformations of all insulin and beta cell measures were made as transformation resulted in more normal distributions. The log transformation of $S_{I}$ was made after a constant of 1 was added to all $S_{I}$ values; this was necessary because of the presence of $S_{I}$ values of 0 in the dataset. Relationships between caffeinated and decaffeinated coffee intakes with the outcome variables of interest were examined in three models: a base model adjusted for age, ethnicity and sex; a second model that additionally adjusted for lifestyle factors and health indicators including smoking status, alcohol intake, energy intake, energy expenditure, waist circumference, history of CVD, presence of hypertension, and family history of diabetes; and a fully adjusted model that additionally included adjustment for intake of the alternate coffee type (decaffeinated or caffeinated) and intakes of fruit and vegetables, wholegrain products, tea, soda, diet soda, and per cent energy intake from saturated fat. Additionally, logistic regression was used to explore the odds of IGT in the population with caffeinated and decaffeinated coffee consumption. The models were the same as those used for the linear regression analysis.

To test the potential for ethnicity, sex, smoking or obesity to modify the relationships between coffee intakes and the measures of insulin sensitivity and secretion, interaction terms of categorical coffee intakes and ethnicity, sex, smoking or obesity were included in the second model for each combination of predictor and outcome variables. Interaction terms were considered significant if $p$ values were $\leq 0.05$. In addition, we tested for non-linearity in the associations of coffee intake with outcome variables using quadratic terms in the models.

Sensitivity analyses were performed for regression analyses to observe if including alternate covariates or additional covariates changed the findings. These included adjusting for BMI rather than waist circumference and 
adding intake of coffee additives to models (honey/sugar, cream, and/or milk).

\section{Results}

Participant characteristics The baseline characteristics of the study population are presented in Table 1 according to total coffee intake per day. Approximately $78 \%$ of the study population consumed less than one serving of coffee a day or did not consume coffee and the median coffee intake for the whole study population was 0.50 servings per day (interquartile range [IQR], 0.07-0.79 servings per day). Only $22 \%$ of the study population consumed one or more servings of coffee per day. Caffeinated coffee intake roughly accounted for $81 \%$ of the total coffee consumed, whereas decaffeinated coffee intake accounted for $19 \%$ of total coffee intake. Sex and ethnicity differed across coffee consumption categories with the highest proportion of women and lowest proportion of Hispanic participants in the group that consumed no coffee and the lowest proportion of African-American participants in the group with the highest coffee consumption. Smoking and alcohol consumption habits also differed across coffee categories, with the highest proportion of current smokers in the highest coffee consumption group and highest proportions of participants that consumed one or more drinks per day found in the two upper levels of coffee consumption. BMI, waist circumference and total energy expenditure did not differ across coffee consumption categories; however, the highest mean energy intake was also observed in the highest coffee intake category. There were no clear differences in intakes of dietary variables across coffee intake categories, though per cent energy from saturated fat intake and vegetable intake differed significantly across groups.

The lowest proportion of participants with IGT was observed in the highest intake category of coffee; $2 \mathrm{~h}$ postload glucose differed significantly across coffee consumption categories with the lowest mean observed in the highest coffee intake group. Proinsulin to C-peptide ratios also differed across coffee intake categories with the lowest intact and split proinsulin to C-peptide ratios observed in the highest intake category.

Caffeinated and decaffeinated coffee intakes were inversely correlated (Spearman correlation coefficient $r=-0.20 ; p<$ 0.0001 ). When participant characteristics were examined across intakes of caffeinated and decaffeinated coffee intakes separately (data not shown), the highest proportion of current smokers was found in the group that consumed no decaffeinated coffee. This group also had the highest proportion of males. Otherwise, participant characteristics were similar across the two types of coffee consumption.
Regression analyses Caffeinated coffee intake was significantly positively associated with $S_{I}$ in all three regression models (Table 2, model 3: $\beta=0.054$; $\mathrm{SE}=0.026 ; p=0.04$ ), where $\beta$ is the regression coefficient, as well as significantly inversely related to $2 \mathrm{~h}$ postload glucose in all models (model 3: $\beta=-0.37$; $\mathrm{SE}=0.10 ; p=0.0003$ ). Initially, caffeinated coffee consumption was also significantly inversely related to fasting insulin (model 1: $\beta=-0.079$; $\mathrm{SE}=$ $0.036 ; p=0.03$ ) but this relationship was attenuated to nonsignificance in model 2.

In general, caffeinated coffee intake was not related to measures of beta cell function. Initially significant inverse relationships were observed between caffeinated coffee intake and the intact and split proinsulin to C-peptide ratios but these relationships were attenuated to non-significance in model 2.

Decaffeinated coffee intake was not found to be related to $\mathrm{S}_{\mathrm{I}}$ or fasting insulin, but was inversely related to $2 \mathrm{~h}$ postload glucose (Table 3, model 3: $\beta=-0.47 ; \mathrm{SE}=0.18 ; p=0.0096$ ). Significant favourable relationships were also observed between decaffeinated coffee consumption and all beta cell function measures. Decaffeinated coffee intake was positively related to AIR (model 3: $\beta=0.19 ; \mathrm{SE}=0.077 ; p=0.0132$ ). Additionally, decaffeinated coffee intake was inversely related to both intact and split proinsulin to $\mathrm{C}$-peptide ratios (intact proinsulin to $\mathrm{C}$-peptide ratio, model 3: $\beta=-0.15 ; \mathrm{SE}=$ 0.061; $p=0.0148$; split proinsulin to $\mathrm{C}$-peptide ratio, model $3: \beta=-0.25 ; \mathrm{SE}=0.068 ; p=0.0002$ ).

Caffeinated coffee was associated with a statistically significant $13 \%$ decreased odds of having IGT in the minimally adjusted model and a significant $16 \%$ decreased odds in the fully adjusted model (Table 4). Decaffeinated coffee intake was borderline significantly associated with a decreased odds of IGT in the fully adjusted model (model 3: OR 0.76 [95\% CI $0.57-1.0], p=0.055$ ).

Interaction and sensitivity analyses There were no significant interactions between sex, ethnicity, smoking, or obesity with caffeinated or decaffeinated coffee intake for any of the outcome variables. Analyses using quadratic terms revealed no evidence of non-linearity in any of the models except for those which assessed the association of: (1) decaffeinated coffee with $\mathrm{S}_{\mathrm{I}}$; and (2) caffeinated coffee with AIR. Additional analyses using categories of coffee consumption in these models did not reveal consistent patterns of association, and there were no significant pairwise differences between coffee consumption categories, adjusting for multiple comparisons (Tukey method; data not shown). Sensitivity analyses included examining the effect of replacing waist circumference with BMI for all regression analyses and additionally adjusting for use of sweeteners, milk and cream in coffee. It was found that these changes to the models did not change the magnitude or significance of the regression coefficients (data not shown). 
Table 1 Participant characteristics by daily coffee consumption $(N=954)$

\begin{tabular}{|c|c|c|c|c|c|c|}
\hline \multirow[t]{2}{*}{ Characteristic } & \multicolumn{5}{|c|}{ Total coffee consumption (servings/day) } & \multirow[t]{2}{*}{$p$ value } \\
\hline & None & $>0$ to $<0.5$ & 0.5 to $<1$ & 1 to $<2$ & $\geq 2$ & \\
\hline$n(\%)$ & $197(20.7)$ & $187(19.6)$ & $361(37.8)$ & $162(17.0)$ & $47(4.9)$ & - \\
\hline Age (years) & $54.6 \pm 8.5$ & $54.5 \pm 8.7$ & $55.4 \pm 8.6$ & $54.7 \pm 7.9$ & $53.9 \pm 9.0$ & 0.6191 \\
\hline Males, $n(\%)$ & $74(37.6)$ & $82(43.9)$ & $159(44.0)$ & $86(53.1)$ & $25(53.2)$ & 0.0379 \\
\hline Ethnicity, $n(\%)$ & & & & & & $<0.0001$ \\
\hline $\begin{array}{l}\text { NHW } \\
\text { AA }\end{array}$ & $\begin{array}{l}90(45.7) \\
65(33.0)\end{array}$ & $\begin{array}{l}61(32.6) \\
84(44.9)\end{array}$ & $\begin{array}{l}129(35.7) \\
65(18.0)\end{array}$ & $\begin{array}{l}78(48.2) \\
19(11.7)\end{array}$ & $\begin{array}{l}26(55.3) \\
4(8.5)\end{array}$ & \\
\hline Hispanic & $42(21.3)$ & $42(22.5)$ & $167(46.3)$ & $65(40.1)$ & $17(36.2)$ & \\
\hline Glucose tolerance status, $n(\%)$ & & & & & & 0.0090 \\
\hline $\begin{array}{l}\text { Normal } \\
\text { IGT }\end{array}$ & $\begin{array}{l}132(67.0) \\
65(33.0)\end{array}$ & $\begin{array}{l}114(61.0) \\
73(39.0)\end{array}$ & $\begin{array}{l}254(70.4) \\
107(29.6)\end{array}$ & $\begin{array}{l}107(66.1) \\
55(34.0)\end{array}$ & $\begin{array}{l}41(87.2) \\
6(12.8)\end{array}$ & \\
\hline Education level completed, $n(\%)$ & & & & & & 0.0001 \\
\hline $\begin{array}{l}\leq \text { Elementary } \\
\leq \text { High school }\end{array}$ & $\begin{array}{l}6(3.1) \\
54(27.4)\end{array}$ & $\begin{array}{l}14(7.5) \\
46(24.6)\end{array}$ & $\begin{array}{l}36(10.0) \\
145(40.2)\end{array}$ & $\begin{array}{l}14(8.6) \\
43(26.5)\end{array}$ & $\begin{array}{l}4(8.5) \\
17(36.2)\end{array}$ & \\
\hline$\leq$ College & $107(54.3)$ & $86(46.0)$ & $131(36.3)$ & $72(44.4)$ & $19(40.4)$ & \\
\hline$\leq$ Graduate school & $30(15.2)$ & $41(21.9)$ & $49(13.6)$ & $33(20.4)$ & $7(14.9)$ & \\
\hline Smoking status, $n(\%)$ & & & & & & $<0.0001$ \\
\hline $\begin{array}{l}\text { Never } \\
\text { Past }\end{array}$ & $\begin{array}{l}123(62.4) \\
55(27.9)\end{array}$ & $\begin{array}{l}91(48.7) \\
72(38.5)\end{array}$ & $\begin{array}{l}164(45.4) \\
131(36.3)\end{array}$ & $\begin{array}{l}54(33.3) \\
84(51.9)\end{array}$ & $\begin{array}{l}6(12.8) \\
20(42.6)\end{array}$ & \\
\hline Current & $19(9.6)$ & $24(12.8)$ & $66(18.3)$ & $24(14.8)$ & $21(44.7)$ & \\
\hline Alcohol intake category, $n(\%)$ & & & & & & $<0.0001$ \\
\hline $\begin{array}{l}\text { Never drank } \\
\text { Ex-drinker }\end{array}$ & $\begin{array}{l}41(20.8) \\
44(22.3)\end{array}$ & $\begin{array}{l}13(7.0) \\
21(11.2)\end{array}$ & $\begin{array}{l}45(12.5) \\
43(11.9)\end{array}$ & $\begin{array}{l}5(3.10 \\
23(14.3)\end{array}$ & $\begin{array}{l}2(4.3) \\
7(14.9)\end{array}$ & \\
\hline Very little & $34(17.3)$ & $35(18.7)$ & $62(17.2)$ & 24 (14.9) & $8(17.0)$ & \\
\hline$<0.5$ drinks/day & $40(20.3)$ & $66(35.3)$ & $109(30.3)$ & $50(31.1)$ & $15(31.9)$ & \\
\hline 0.5 to $<1$ drinks/day & $15(7.6)$ & $21(11.2)$ & $37(10.3)$ & $18(11.2)$ & $3(6.4)$ & \\
\hline 1 to $<3$ drinks/day & $17(8.6)$ & $27(14.4)$ & $50(13.9)$ & $32(19.90$ & $9(19.2)$ & \\
\hline$\geq 3$ drinks/day & $6(3.1)$ & $4(2.1)$ & $14(3.9)$ & $9(5.6)$ & $3(6.4)$ & \\
\hline History of CVD, $n(\%)$ & $10(5.1)$ & $9(4.8)$ & $18(5.0)$ & $5(3.1)$ & $2(4.3)$ & 0.8944 \\
\hline Family history of diabetes, $n(\%)$ & $69(35.0)$ & $75(40.1)$ & $148(41.0)$ & $68(42.0)$ & $12(25.5)$ & 0.1849 \\
\hline Hypertension, $n(\%)$ & $65(33.0)$ & $66(35.5)$ & $118(32.8)$ & $44(27.7)$ & $13(27.7)$ & 0.5638 \\
\hline Total energy intake (kJ/day) & $7,507 \pm 3,004$ & $6,952 \pm 2,906$ & $8,023 \pm 3,285$ & $8,836 \pm 3,296$ & $9,007 \pm 3,219$ & $<0.0001$ \\
\hline $\begin{array}{l}\text { Total energy expended } \\
\left(\mathrm{kJ} \mathrm{kg}^{-1} \mathrm{day}^{-1}\right)\end{array}$ & $160(148-187)$ & $158(147-174)$ & $164(149-186)$ & $162(150-182)$ & $164(149-184)$ & 0.0862 \\
\hline BMI $\left(\mathrm{kg} / \mathrm{m}^{2}\right)$ & $28.4 \pm 5.6$ & $28.7 \pm 6.1$ & $28.2 \pm 5.3$ & $28.4 \pm 5.9$ & $26.7 \pm 5.1$ & 0.3187 \\
\hline Waist circumference (cm) & $89.1 \pm 12.9$ & $91.4 \pm 13.3$ & $90.2 \pm 12.2$ & $91.6 \pm 12.8$ & $88.9 \pm 12.5$ & 0.2468 \\
\hline $2 \mathrm{~h}$ glucose $(\mathrm{mmol} / \mathrm{l})$ & $7.11 \pm 1.93$ & $7.13 \pm 1.80$ & $6.80 \pm 1.85$ & $6.71 \pm 1.91$ & $5.91 \pm 1.43$ & 0.0003 \\
\hline Fasting insulin (pmol/1) & $93.8(55.6-135.4)$ & $90.3(62.5-132.0)$ & $90.3(62.5-125.0)$ & $83.3(55.6-132.0)$ & $69.5(55.6-104.2)$ & 0.0625 \\
\hline $\begin{array}{l}\text { Insulin sensitivity }\left(\times 10^{-4} \mathrm{~min}^{-1}\right. \\
\left.\left[\mu \mathrm{U}^{\prime} \mathrm{ml}\right]^{-1}\right)^{\mathrm{a}}\end{array}$ & $1.53(0.88-2.95)$ & $1.61(0.94-2.87)$ & $1.61(0.90-3.01)$ & $1.72(0.91-2.85)$ & $2.49(1.13-3.83)$ & 0.1611 \\
\hline Acute insulin response $(\mu \mathrm{U} / \mathrm{ml})^{\mathrm{b}}$ & $48.0(27.5-87.5)$ & $50.5(25.8-81.0)$ & $53.0(32.0-87.5)$ & $47.8(24.5-81.0)$ & $64.5(36.5-95.5)$ & 0.1245 \\
\hline Intact proinsulin $(\mathrm{pmol} / \mathrm{l}) / \mathrm{C}$-peptide & $9.3(6.8-12.7)$ & $10.4(7.2-15.6)$ & $8.6(6.2-12.4)$ & $8.7(6.4-13.2)$ & $6.9(5.6-11.8)$ & 0.0023 \\
\hline Split proinsulin (pmol/1)/C-peptide & $11.5(7.8-16.4)$ & $13.1(8.7-17.0)$ & $11.0(7.6-16.3)$ & $10.5(7.5-16.7)$ & $8.6(5.9-14.2)$ & 0.0318 \\
\hline \multicolumn{7}{|l|}{ Dietary variables ${ }^{\mathrm{c}}$} \\
\hline Wholegrain intake (servings/day) & $0.88(0.78-0.98)$ & $0.77(0.66-0.87)$ & $0.79(0.72-0.87)$ & $0.85(0.73-0.96)$ & $0.76(0.55-0.97)$ & 0.4961 \\
\hline Vegetable intake (servings/day) & $3.1(2.9-3.4)$ & $2.9(2.6-3.1)$ & $3.4(3.2-3.5)$ & $3.2(2.9-3.5)$ & $3.4(2.9-3.9)$ & 0.0356 \\
\hline Fruit intake (servings/day) & $1.7(1.5-1.9)$ & $1.6(1.4-1.7)$ & $1.7(1.5-1.8)$ & $1.5(1.3-1.7)$ & $1.5(1.1-1.9)$ & 0.6393 \\
\hline$\%$ Energy from saturated fat & $11.9(11.4-12.3)$ & $11.8(11.4-12.3)$ & $12.5(12.1-12.8)$ & $12.7(12.2-13.2)$ & $12.4(11.5-13.2)$ & 0.0220 \\
\hline
\end{tabular}

Data are presented as mean $\pm \mathrm{SD}$, median (IQR) or $n(\%)$ unless otherwise specified

AA, African-American; NHW, non-Hispanic white

${ }^{\mathrm{a}}$ To convert values to SI units $\left(\times 10^{-4} \mathrm{~min}^{-1}[\mathrm{pmol} / 1]^{-1}\right)$ multiply by 0.167

${ }^{\mathrm{b}}$ To convert values to SI units (pmol/1) multiply by 6.945

${ }^{\mathrm{c}}$ Dietary variables presented as least-square means $(95 \% \mathrm{CI})$ adjusted for energy intake 
Table 2 Multiple regression analyses for caffeinated coffee intake with measures of insulin sensitivity and secretion

Outcome variable Caffeinated coffee consumption (servings/day)

$n \quad \beta \quad$ SE $\quad p$ value

Log insulin sensitivity

\begin{tabular}{|c|c|c|c|c|}
\hline Model $1^{\mathrm{a}}$ & 940 & 0.081 & 0.030 & 0.0067 \\
\hline Model $2^{\mathrm{b}}$ & 940 & 0.058 & 0.026 & 0.0234 \\
\hline Model $3^{\mathrm{c}}$ & 940 & 0.054 & 0.026 & 0.0378 \\
\hline \multicolumn{5}{|c|}{ Log fasting insulin } \\
\hline Model $1^{\mathrm{a}}$ & 938 & -0.079 & 0.036 & 0.0270 \\
\hline Model $2^{\mathrm{b}}$ & 938 & -0.060 & 0.031 & 0.0589 \\
\hline Model $3^{\mathrm{c}}$ & 938 & -0.059 & 0.032 & 0.0654 \\
\hline \multicolumn{5}{|c|}{$2 \mathrm{~h}$ postload glucose } \\
\hline Model $1^{\mathrm{a}}$ & 940 & -0.393 & 0.103 & 0.0002 \\
\hline Model $2^{\mathrm{b}}$ & 940 & -0.346 & 0.100 & 0.0006 \\
\hline Model $3^{\mathrm{c}}$ & 940 & -0.368 & 0.101 & 0.0003 \\
\hline \multicolumn{5}{|c|}{ Log acute insulin response ${ }^{\mathrm{d}}$} \\
\hline Model $1^{\mathrm{a}}$ & 940 & 0.061 & 0.041 & 0.1397 \\
\hline Model $2^{\mathrm{b}}$ & 940 & 0.053 & 0.042 & 0.2098 \\
\hline Model $3^{\mathrm{c}}$ & 940 & 0.063 & 0.043 & 0.1452 \\
\hline \multicolumn{5}{|c|}{ Log intact proinsulin to C-peptide ratio } \\
\hline Model $1^{\mathrm{a}}$ & 788 & -0.069 & 0.032 & 0.0311 \\
\hline Model $2^{\mathrm{b}}$ & 788 & -0.046 & 0.033 & 0.1608 \\
\hline Model $3^{\mathrm{c}}$ & 788 & -0.053 & 0.033 & 0.1114 \\
\hline \multicolumn{5}{|c|}{ Log split proinsulin to C-peptide ratio } \\
\hline Model $1^{\mathrm{a}}$ & 788 & -0.076 & 0.037 & 0.0397 \\
\hline Model $2^{\mathrm{b}}$ & 788 & -0.043 & 0.036 & 0.2391 \\
\hline Model $3^{\mathrm{c}}$ & 788 & -0.056 & 0.037 & 0.1292 \\
\hline
\end{tabular}

Interpretation of statistically significant $\beta$ regression coefficients in model 3: when caffeinated coffee intake changes from 0 to 2 servings per day, the fully adjusted model predicted an increase in $\mathrm{S}_{\mathrm{I}}$ of 0.27 units and a decrease in $2 \mathrm{~h}$ postload glucose of $0.74 \mathrm{mmol} / \mathrm{l}$, while holding all other variables in the model constant

${ }^{a}$ Adjusted for age, sex and ethnicity

${ }^{\mathrm{b}}$ Adjusted for variables in the previous model as well as waist circumference, education level, total energy intake, smoking status, total estimated energy expenditure, alcohol consumption category, history of CVD, family history of diabetes, and baseline hypertension

${ }^{\mathrm{c}}$ Adjusted for variables in the previous model as well as decaffeinated coffee consumption, vegetable intake, fruit intake, $\%$ energy from saturated fat, and intakes of wholegrain, tea, soda and diet soda

${ }^{\mathrm{d}}$ Additionally adjusted for insulin sensitivity in all models

\section{Discussion}

In this non-diabetic, multi-ethnic population, we found that caffeinated coffee intake was significantly positively related to $\mathrm{S}_{\mathrm{I}}$ and strongly inversely related to $2 \mathrm{~h}$ postload glucose. Interestingly, decaffeinated coffee intake was favourably related to measures of beta cell function, which included a significant positive relationship with AIR and significant inverse relationships with intact and split proinsulin to Cpeptide ratios.

Our study supports current data that indicate that there may be a protective effect of coffee consumption on the risk of diabetes. Development of insulin resistance and impaired beta cell function are the two key defects in physiological

Table 3 Multiple regression analyses for decaffeinated coffee intake with measures of insulin sensitivity and secretion

\begin{tabular}{ccccc} 
Outcome variable & \multicolumn{4}{l}{ Decaffeinated coffee consumption (servings/day) } \\
\cline { 2 - 5 } & $n$ & $\beta$ & $\mathrm{SE}$ & $p$ value
\end{tabular}

Log insulin sensitivity

$\begin{array}{lllll}\text { Model } 1^{\mathrm{a}} & 940 & 0.014 & 0.056 & 0.7976 \\ \text { Model } 2^{\mathrm{b}} & 940 & 0.027 & 0.046 & 0.5539 \\ \text { Model } 3^{\mathrm{c}} & 940 & 0.030 & 0.047 & 0.5246\end{array}$

Log fasting insulin

$\begin{array}{lllll}\text { Model } 1^{\mathrm{a}} & 938 & -0.018 & 0.066 & 0.79 \\ \text { Model } 2^{\mathrm{b}} & 938 & -0.029 & 0.056 & 0.6017 \\ \text { Model } 3^{\mathrm{c}} & 938 & -0.042 & 0.057 & 0.4578\end{array}$

$2 \mathrm{~h}$ postload glucose

$\begin{array}{lllll}\text { Model } 1^{\mathrm{a}} & 940 & -0.423 & 0.193 & 0.0286 \\ \text { Model } 2^{\mathrm{b}} & 940 & -0.459 & 0.179 & 0.0105 \\ \text { Model } 3^{\mathrm{c}} & 940 & -0.467 & 0.180 & 0.0096\end{array}$

Log acute insulin response ${ }^{\mathrm{d}}$

$\begin{array}{lllll}\text { Model } 1^{\mathrm{a}} & 940 & 0.161 & 0.076 & 0.0340 \\ \text { Model } 2^{\mathrm{b}} & 940 & 0.160 & 0.075 & 0.0340 \\ \text { Model } 3^{\mathrm{c}} & 940 & 0.191 & 0.077 & 0.0132\end{array}$

Log intact proinsulin to C-peptide ratio

$\begin{array}{lllll}\text { Model } 1^{\mathrm{a}} & 788 & -0.152 & 0.061 & 0.0135 \\ \text { Model } 2^{\mathrm{b}} & 788 & -0.137 & 0.060 & 0.0241 \\ \text { Model } 3^{\mathrm{c}} & 788 & -0.150 & 0.061 & 0.0148\end{array}$

Log split proinsulin to C-peptide ratio

\begin{tabular}{|c|c|c|c|c|}
\hline Model $1^{\mathrm{a}}$ & 788 & -0.239 & 0.071 & 0.0008 \\
\hline Model $2^{\mathrm{b}}$ & 788 & -0.230 & 0.067 & 0.0006 \\
\hline Model $3^{\mathrm{c}}$ & 788 & -0.254 & 0.068 & 0.0002 \\
\hline
\end{tabular}

Interpretation of statistically significant $\beta$ regression coefficients in model 3: when decaffeinated coffee intake changes from 0 to 2 servings per day, the fully adjusted model predicted an increase in AIR of $17.52 \mu \mathrm{U} / \mathrm{ml}$ (to convert value to SI units [pmol $/ \mathrm{ml}$ ] multiply by 6.945), a decrease in $2 \mathrm{~h}$ postload glucose of $0.93 \mathrm{mmol} / \mathrm{l}$, and a decrease in intact and split proinsulin to C-peptide ratios of 3.04 and 4.27 , respectively, while holding all other variables in the model constant

${ }^{\text {a }}$ Adjusted for age, sex and ethnicity

${ }^{\mathrm{b}}$ Adjusted for variables in the previous model as well as waist circumference, education level, total energy intake, smoking status, total estimated energy expenditure, alcohol consumption category, history of CVD, family history of diabetes, and baseline hypertension

${ }^{\mathrm{c}}$ Adjusted for variables in the previous model as well as caffeinated coffee consumption, vegetable intake, fruit intake, $\%$ energy from saturated fat, and intakes of wholegrain, tea, soda and diet soda

${ }^{\mathrm{d}}$ Additionally adjusted for insulin sensitivity in all models 
Table 4 Multiple logistic regression analyses of coffee intakes and odds of impaired glucose tolerance $(N=940)$

\begin{tabular}{|c|c|c|c|}
\hline \multirow[t]{2}{*}{ Independent variable } & \multicolumn{3}{|c|}{ Risk of impaired glucose tolerance } \\
\hline & $\mathrm{OR}^{\mathrm{a}}(95 \% \mathrm{CI})$ & Wald $\chi^{2}$ & $p$ value \\
\hline \multicolumn{4}{|c|}{ Caffeinated coffee intake } \\
\hline Model $1^{\mathrm{b}}$ & $0.87(0.76-0.99)$ & 4.53 & 0.0334 \\
\hline Model $2^{\mathrm{c}}$ & $0.87(0.75-1.01)$ & 3.50 & 0.0613 \\
\hline Model $3^{\mathrm{d}}$ & $0.84(0.72-0.98)$ & 5.13 & 0.0235 \\
\hline \multicolumn{4}{|c|}{ Decaffeinated coffee intake } \\
\hline Model $1^{\mathrm{b}}$ & $0.83(0.65-1.06)$ & 2.25 & 0.1338 \\
\hline Model $2^{\mathrm{c}}$ & $0.77(0.58-1.01)$ & 3.64 & 0.0562 \\
\hline Model $3^{\mathrm{d}}$ & $0.76(0.57-1.01)$ & 3.67 & 0.0553 \\
\hline
\end{tabular}

${ }^{\mathrm{a}} \mathrm{OR}$ refers to risk of IGT per 0.5 serving increase in coffee intake

${ }^{\mathrm{b}}$ Adjusted for age, sex and ethnicity

${ }^{\mathrm{c}}$ Adjusted for variables in the previous model as well as waist circumference, education level, total energy intake, smoking status, total estimated energy expenditure, alcohol consumption category, history of CVD, family history of diabetes, and baseline hypertension

${ }^{\mathrm{d}}$ Adjusted for variables in the previous model as well as caffeinated coffee consumption, vegetable intake, fruit intake, $\%$ energy from saturated fat, wholegrain intake, tea, soda, and diet soda consumption

function that lead to type 2 diabetes mellitus. Our crosssectional analysis showed that caffeinated coffee intake was positively related to $\mathrm{S}_{\mathrm{I}}$, a finding that is consistent with the inverse relationship observed between HOMA-IR (a measure of insulin resistance) in women with NGT and IGT in a Swedish study population [2] and in men and women in a Dutch study population [4]. The result is also consistent with a positive relationship observed between caffeinated coffee and $\mathrm{S}_{\mathrm{I}}$, measured by a hyperinsulinaemic-euglycaemic clamp, amongst elderly Swedish men [3]. Although acute and short-term intervention studies [10-12] have shown caffeine and caffeinated coffee intake to reduce $S_{I}$, our data support the initial findings from the aforementioned observational studies that habitual caffeinated coffee consumption may be related to higher $\mathrm{S}_{\mathrm{I}}$, though the causal association between these variables cannot be assumed from this cross-sectional observational analysis. A longterm randomised controlled trial that examines the effect of regular caffeinated coffee consumption on $\mathrm{S}_{\mathrm{I}}$ is warranted.

Interestingly, our study showed that decaffeinated coffee intake was favourably related to beta cell function measured by AIR and proinsulin to C-peptide ratios. Data on the relationships between coffee consumption and measures of beta cell function are scarce, although Agardh et al. [2] reported an inverse relationship between coffee consumption and HOMA-beta cell in women, but not men, with NGT and IGT. Arnlov et al. [3] reported no association between coffee intake and early insulin response measured from an OGTT in an elderly population of men from
Sweden. Of note is that both studies did not distinguish between caffeinated and decaffeinated coffee. The measures of beta cell function used in our study were also more detailed assessments of beta cell function. As a sensitivity analysis, we examined the interaction of caffeinated and decaffeinated coffee intakes with sex when AIR was an outcome measure; the interaction terms were not significant $(p>0.65)$, so we did not stratify our analyses by sex.

We found that both caffeinated coffee and decaffeinated coffee consumption were inversely associated with $2 \mathrm{~h}$ postload glucose. These results support the other findings in our study of a relationship between caffeinated coffee consumption and $\mathrm{S}_{\mathrm{I}}$, and decaffeinated coffee and AIR, as both insulin resistance and impaired beta cell function are known to contribute to an impaired response to a glucose load. These findings are consistent with those of van Dam et al. [4], who also found an inverse relationship between coffee consumption and $2 \mathrm{~h}$ postload glucose.

These findings provide insight into a potential mechanism by which coffee may be protective against type 2 diabetes mellitus, and support previous findings that decaffeinated coffee intake may have a stronger protective effect than caffeinated coffee intake [1]. Impairment in beta cell function has been identified as a crucial physiological change responsible for the conversion to type 2 diabetes mellitus. It has been suggested that the polyphenol content in coffee, mainly in the form of chlorogenic acid, may protect beta cells from oxidative stress [13]. We saw stronger relationships between decaffeinated coffee intake and beta cell function measures than between caffeinated coffee intake and beta cell function measures, which may indicate that the caffeine content, the most obvious difference between these beverages, may counteract the protective effect of the other protective substances in coffee. In addition, our study indicates that, mechanistically, caffeinated coffee intake may affect a different physiological pathway, specifically, via $\mathrm{S}_{\mathrm{I}}$ rather than beta cell function. However, this explanation for the different relationships we observed between coffee types and insulin measures is merely speculative and further explorations of these relationships are necessary. Regarding the consistent protective effect of caffeinated coffee intake on the incidence of type 2 diabetes mellitus that has been reported [1], it is conceivable that the antioxidants in caffeinated coffee could have an overall positive effect on diabetes risk and that caffeine could have a smaller negative effect.

The strengths of this study include the use of precise measures of $\mathrm{S}_{\mathrm{I}}$ and beta cell function and extensive data on potential confounding variables. Additionally, the study population included three ethnic groups, allowing for greater generalisability of the results. The ability to separate caffeinated coffee intake from decaffeinated coffee intake represents an additional strength of this study, as studies 
that have looked at the association between coffee intake and $\mathrm{S}_{\mathrm{I}}$ and beta cell function measures have not distinguished between coffee types [2-4]. Our results indicated that caffeinated and decaffeinated coffee intake relate differently to $S_{I}$ and beta cell function, suggesting that it may be important to differentiate between these coffee types. Importantly, the measures of $\mathrm{S}_{\mathrm{I}}$ and AIR obtained from the FSIGT are highly precise measures which closely correlate with measures of these variables from the hyperinsulinaemic-euglycaemic and hyperglycaemic clamp techniques. Other studies which have examined coffee intake in relation to measures of insulin resistance and beta cell function relied on less optimal measures of these variables, which included HOMA-IR [2, 4], HOMA-beta cell [2], and C-peptide [2, 4, 14]. One exception was the study by Arnlov et al. [3], which looked at coffee consumption in relation to $\mathrm{S}_{\mathrm{I}}$ measured by hyperinsulinaemic-euglycaemic clamp.

A number of potential limitations should be considered when interpreting the results of this study. Notably, the analysis was cross-sectional, which does not allow for conclusions on the causality or temporality of the relationships between caffeinated and decaffeinated coffee with measures of $S_{I}$ and insulin secretion to be made. As this was an observational study, it is also possible that residual confounding could have occurred, although the covariates included in the regression models were carefully considered and covered a large breadth of potential confounding variables. It has been observed that coffee consumption is associated with non-optimal health behaviours [15] which may not have been fully captured by the covariates in our regression models. Our measure of coffee intake relied on data from a semi-quantitative FFQ and participantidentified ranking of serving size, which resulted in a non-quantified measure of coffee intake. This could have resulted in misclassification of coffee intakes. Other studies have specified a volume of serving size in their dietary questionnaires [4, 16-18], which may result in greater accuracy of estimated coffee intake. However, as discussed by van Dam [15], it is difficult to draw conclusions about the protective effect of coffee at a particular level of consumption from the majority of studies due to their use of non-quantified measure of coffee intake and differing definitions of 'cup size' [15]. Similarly, one potential limitation of our study is the narrow range of coffee consumption observed in the study population, which may have limited the ability to fully capture the scope of the relationships between coffee and insulin measures. In many of the prospective analyses conducted, the protective effects of coffee intake have been observed at high levels of consumption (i.e. $\geq 4 \mathrm{cups} /$ day) $[16,19-24]$. However, because serving size was a ranked measure in our study, it is difficult to draw conclusions about the level of coffee actually consumed in comparison to other studies. Further, the FFQ used in this study did not allow us to capture the full spectrum of caffeine containing foods and beverages.

Our study is also limited in that it did not collect information on the time of day that coffee was consumed. As was recently explored in an analysis by Sartorelli et al. [18], the time of day may impact the protective effect of coffee on diabetes risk. Intervention studies have also shown coffee to have acute postprandial effects on glucose absorption when consumed with a meal as well as to have second meal effects [13]. In addition, as identified by van Dam [15], numerous factors affect the dose of coffee consumed, which in turn could affect the biological activity of coffee on physiological actions related to diabetes. These include the strength of the brew, the type of coffee beans used, and the amount of coffee consumed [15]. Studies that include more specific details about these factors would allow for greater elucidation of the relationship between coffee consumption and measures of $S_{I}$ and insulin secretion.

In conclusion, we found in this cross-sectional study that caffeinated coffee intake was positively related to $S_{I}$ and that decaffeinated coffee intake was favourably related to measures of beta cell function. This study provides insight into the potential pathophysiological pathways through which coffee consumption could affect the risk of type 2 diabetes mellitus and provides a foundation for further exploration of these relationships.

Acknowledgements A.J. Hanley holds a Tier II Canada Research Chair in Diabetes Epidemiology. IRAS was supported by National Heart, Lung and Blood Institute grants U01-HL47887, U01-HL47889, U01-HL47892, U01-HL47902, DK-29867, and R01 58329 and grant M01-RR-43 from the National Institutes of Health.

Duality of interest The authors declare that there is no duality of interest associated with this manuscript.

\section{References}

1. Huxley R, Lee CM, Barzi F et al (2009) Coffee, decaffeinated coffee, and tea consumption in relation to incident type 2 diabetes mellitus: a systematic review with meta-analysis. Arch Intern Med 169:2053-2063

2. Agardh EE, Carlsson S, Ahlbom A et al (2004) Coffee consumption, type 2 diabetes and impaired glucose tolerance in Swedish men and women. J Intern Med 255:645-652

3. Arnlov J, Vessby B, Riserus U (2004) Coffee consumption and insulin sensitivity. JAMA 291:1199-1201

4. van Dam RM, Dekker JM, Nijpels G, Stehouwer CD, Bouter LM, Heine RJ (2004) Coffee consumption and incidence of impaired fasting glucose, impaired glucose tolerance, and type 2 diabetes: the Hoorn Study. Diabetologia 47:2152-2159

5. Wagenknecht LE, Mayer EJ, Rewers M et al (1995) The Insulin Resistance Atherosclerosis Study (IRAS) objectives, design, and recruitment results. Ann Epidemiol 5:464-472 
6. Mayer-Davis EJ, D'Agostino R Jr, Karter AJ et al (1998) Intensity and amount of physical activity in relation to insulin sensitivity: the Insulin Resistance Atherosclerosis Study. JAMA 279:669-674

7. Mayer-Davis EJ, Vitolins MZ, Carmichael SL et al (1999) Validity and reproducibility of a food frequency interview in a Multi-Cultural Epidemiology Study. Ann Epidemiol 9:314-324

8. Liese AD, Schulz M, Moore CG, Mayer-Davis EJ (2004) Dietary patterns, insulin sensitivity and adiposity in the multi-ethnic Insulin Resistance Atherosclerosis Study population. Br J Nutr 92:973-984

9. Festa A, Williams K, Hanley AJ, Haffner SM (2008) Beta-cell dysfunction in subjects with impaired glucose tolerance and early type 2 diabetes: comparison of surrogate markers with first-phase insulin secretion from an intravenous glucose tolerance test. Diabetes 57:1638-1644

10. Dekker MJ, Gusba JE, Robinson LE, Graham TE (2007) Glucose homeostasis remains altered by acute caffeine ingestion following 2 weeks of daily caffeine consumption in previously non-caffeineconsuming males. Br J Nutr 98:556-562

11. Moisey LL, Kacker S, Bickerton AC, Robinson LE, Graham TE (2008) Caffeinated coffee consumption impairs blood glucose homeostasis in response to high and low glycemic index meals in healthy men. Am J Clin Nutr 87:1254-1261

12. Moisey LL, Robinson LE, Graham TE (2010) Consumption of caffeinated coffee and a high carbohydrate meal affects postprandial metabolism of a subsequent oral glucose tolerance test in young, healthy males. Br J Nutr 103:833-841

13. Tunnicliffe JM, Shearer J (2008) Coffee, glucose homeostasis, and insulin resistance: physiological mechanisms and mediators. Appl Physiol Nutr Metab 33:1290-1300

14. Wu T, Willett WC, Hankinson SE, Giovannucci E (2005) Caffeinated coffee, decaffeinated coffee, and caffeine in relation to plasma C-peptide levels, a marker of insulin secretion, in U.S. women. Diab Care 28:1390-1396
15. van Dam RM (2008) Coffee consumption and risk of type 2 diabetes, cardiovascular diseases, and cancer. Appl Physiol Nutr Metab 33:1269-1283

16. Fuhrman BJ, Smit E, Crespo CJ, Garcia-Palmieri MR (2009) Coffee intake and risk of incident diabetes in Puerto Rican men: results from the Puerto Rico Heart Health Program. Public Health Nutr 12:842-848

17. Hu G, Jousilahti P, Peltonen M, Bidel S, Tuomilehto J (2006) Joint association of coffee consumption and other factors to the risk of type 2 diabetes: a prospective study in Finland. Int J Obes (Lond) 30:1742-1749

18. Sartorelli DS, Fagherazzi G, Balkau B et al (2010) Differential effects of coffee on the risk of type 2 diabetes according to meal consumption in a French cohort of women: the E3N/EPIC cohort study. Am J Clin Nutr 91:1002-1012

19. Carlsson S, Hammar N, Grill V, Kaprio J (2004) Coffee consumption and risk of type 2 diabetes in Finnish twins. Int $\mathrm{J}$ Epidemiol 33:616-617

20. Odegaard AO, Pereira MA, Koh WP, Arakawa K, Lee HP, Yu MC (2008) Coffee, tea, and incident type 2 diabetes: the Singapore Chinese Health Study. Am J Clin Nutr 88:979-985

21. Paynter NP, Yeh HC, Voutilainen S et al (2006) Coffee and sweetened beverage consumption and the risk of type 2 diabetes mellitus: the atherosclerosis risk in communities study. Am J Epidemiol 164:1075-1084

22. Salazar-Martinez E, Willett WC, Ascherio A et al (2004) Coffee consumption and risk for type 2 diabetes mellitus. Ann Intern Med $140: 1-8$

23. Tuomilehto J, Hu G, Bidel S, Lindstrom J, Jousilahti P (2004) Coffee consumption and risk of type 2 diabetes mellitus among middle-aged Finnish men and women. JAMA 291:1213-1219

24. van Dam RM, Feskens EJ (2002) Coffee consumption and risk of type 2 diabetes mellitus. Lancet 360:1477-1478 